\title{
Evidence That the Laminar Fate of LGE/CGE-Derived Neocortical Interneurons Is Dependent on Their Progenitor Domains
}

\author{
Makio Torigoe, Kenta Yamauchi, Toshiya Kimura, Yo Uemura, and Fujio Murakami \\ Graduate School of Frontier Biosciences, Osaka University, Suita, Osaka 560-8531, Japan
}

Neocortical interneurons show tremendous diversity in terms of their neurochemical marker expressions, morphology, electrophysiological properties, and laminar fate. Allocation of interneurons to their appropriate regions and layers in the neocortex is thought to play important roles for the emergence of higher functions of the neocortex. Neocortical interneurons mainly originate from the medial ganglionic eminence (MGE) and the caudal ganglionic eminence (CGE). The diversity and the laminar fate of MGE-derived interneurons depend on the location of their birth and birthdate, respectively. However, this relationship does not hold for CGE-derived interneurons. Here, using the method of in utero electroporation, which causes arbitrary occurrence of labeled progenitor domains, we tracked all descendants of the lateral ganglionic eminence (LGE)/CGE progenitors in mice. We provide evidence that neocortical interneurons with distinct laminar fate originate from distinct progenitor domains within the LGE/CGE. We find layer I interneurons are predominantly labeled in a set of animals, whereas other upper layer neurons are predominantly labeled in another set. We also find distinct subcortical structures labeled between the two sets. Further, interneurons labeled in layer I show distinct neurochemical properties from those in other layers. Together, these results suggest that the laminar fate of LGE/CGE-derived interneurons depends on their spatial origin.

Key words: caudal ganglionic eminence; cortex; in utero electroporation; interneuron; laminar fate

\section{Significance Statement}

Diverse types of neocortical interneurons have distinct laminar fate, neurochemical marker expression, morphology, and electrophysiological properties. Although the specifications and laminar fate of medial ganglionic eminence-derived neocortical interneurons depend on their location of embryonic origin and birthdate, no similar causality of lateral/caudal ganglionic eminence (LGE/CGE)-derived neocortical interneurons is known. Here, we performed in utero electroporation on mouse LGE/CGE and found two groups of animals, one with preferential labeling of layer I and the other with preferential labeling of other layers. Interneurons labeled in these two groups show distinct neurochemical properties and morphologies and are associated with labeling of distinct subcortical structures. These findings suggest that the laminar fate of LGE/CGE-derived neocortical interneurons depends on their spatial origin.

\section{Introduction}

The neocortex consists of two major classes of neurons, excitatory pyramidal neurons and inhibitory interneurons. Although neocortical interneurons comprise only $20-30 \%$ of the cortical neuronal population, they have tremendous diversity in terms of molecular expression, morphological features, electrophysio-

\footnotetext{
Received Sept. 23, 2015; revised Jan. 6, 2016; accepted Jan. 8, 2016.

Author contributions: F.M. designed research; M.T., Y.U., and F.M. performed research; M.T. and F.M. analyzed data; K.Y., T.K., and F.M. wrote the paper.

This work was supported by a Grant-in-Aid for Scientific Research (KAKENHI, 22220004 and 23123511) from the Ministry of Education, Culture, Sports, Science and Technology (Japan) to F.M. We thank Dr. Yoshiko Takahashi for the pT2K-CAGGS-EGFP, Dr. Koichi Kawakami for the PCAGGS-T2TP, Dr. Jun-Ichi Miyazaki for the pCAGGS, and pCAGGSCre plasmid vectors and Dr. Roger Y. Tsien for the mCherry and tdTomato. We also thank Dr. Goichi Miyoshi for his helpful discussion, Dr. Teruyoshi Hirayama for his advice on immunostaining for GABA, Peter Karagiannis for critical reading of the manuscript and Tomoko Onishi for technical assistance.

The authors declare no competing financial interests.
}

logical properties, and laminar distribution (for review, see Markram et al., 2004; Bartolini et al., 2013). The diversity correlates with proper spatial distribution and the resulting synaptic connections are key for the emergence of neocortex functions (Kepecs and Fishell, 2014).

A number of studies have addressed the developmental mechanisms that lead to the different laminar fate and subtypes caused by this diversity. This issue has been most extensively studied for

Correspondence should be addressed to Fujio Murakami, Graduate School of Frontier Biosciences, Osaka University, Suita, 0saka 560-8531, Japan. E-mail:murakami@fbs.osaka-u.ac.jp.

M. Torigoe's present address: Lab. Dev Gene Regulation, RIKEN, BSI, 2-1 Hirosawa, Wako, 351-0198, Saitama, Japan.

K. Yamauchi's present address: Div of Brain Function, Natl Inst Genetics, 1111 Yata, Mishima 411-8540, Shizuoka Japan.

T. Kimura's present address: RIKEN Cent Dev Biol Kobe, Hyogo 650-0047, Japan.

DOI:10.1523/JNEUROSCI.3550-15.2016

Copyright $\odot 2016$ the authors $\quad 0270-6474 / 16 / 362044-13 \$ 15.00 / 0$ 
the interneurons derived from the medial ganglionic eminence (MGE), which is the major source for neocortical interneurons. It has been shown that both the time and location of embryonic origin are important for the fate of MGE-derived interneurons (for review, see Wonders and Anderson, 2006; Gelman and Marín, 2010). For example, somatostatin-positive $\left(\mathrm{SST}^{+}\right)$interneurons largely originate from the dorsal MGE, whereas fastspiking parvalbumin-positive $\left(\mathrm{PV}^{+}\right)$interneurons originate preferentially from the ventral MGE (Flames et al., 2007; Fogarty et al., 2007; Ghanem et al., 2007; Wonders et al., 2008). The laminar fate of MGE-derived interneurons depends on the cells' birthdate in an "inside-out" manner (Fairén et al., 1986; Valcanis and Tan, 2003; Miyoshi et al., 2007; Rymar and Sadikot, 2007), as is the case for cortical excitatory neurons (Angevine and Sidman, 1961; Takahashi et al., 1999).

The caudal ganglionic eminence (CGE) is the second largest source of neocortical interneurons (for review, see Gelman and Marín, 2010; Rudy et al., 2011), although the preoptic area (POA) also generates a small number of interneurons (Nery et al., 2002; Gelman et al., 2009). Like the MGE, the CGE generates neurochemically, morphologically, and electrophysiologically diverse types of interneurons (Lee et al., 2010; Miyoshi et al., 2010; Vucurovic et al., 2010). For example, there are subsets of interneurons that express vasoactive intestinal peptide (VIP), reelin (RLN), calretinin, neuropeptide Y (NPY), or their combination (Lee et al., 2010; Miyoshi et al., 2010; Rubin et al., 2010; Ma et al., 2012; Miyoshi et al., 2015). Some interneurons extend radially oriented processes, whereas others show multipolar shape and neurogliaform morphology (Hajós et al., 1988; Kawaguchi and Kubota, 1996; Lee et al., 2010; Miyoshi et al., 2010). However, no specific progenitor domain (PD) within the CGE is known to contribute to specific subtypes. Furthermore, whereas the CGE contributes to neocortical interneurons in all layers (Lee et al., 2010; Miyoshi et al., 2010; Vucurovic et al., 2010; Miyoshi and Fishell, 2011; Ma et al., 2012), neither the laminar fate nor neurochemical phenotype of neocortical interneurons correlates well with their birthdate (Miyoshi et al., 2010). Therefore, the factors that govern the diversity and laminar fate of CGE-derived interneurons remain elusive.

In this study, we took advantage of the fact that in utero electroporation (IUE) at embryonic day 10.5 (E10.5) preferentially labels progenitors in the lateral ganglionic eminence (LGE) and CGE (Torigoe et al., 2015) and tracked all descendants of labeled progenitors using the Tol-2 system (Kawakami et al., 2004a, 2004b). We found that labeled interneurons are preferentially localized to the upper layers in most animals, a feature characteristic of LGE/CGE-derived neocortical interneurons. We show evidence that distinct PDs within the LGE/CGE give rise to interneurons with distinct laminar fate. Although layer I interneurons were predominantly labeled in a set of animals, those in other upper layers were predominantly labeled in a different set of animals. Between these two sets, distinct subcortical regions were labeled, suggesting that labeled PDs are distinct between the two groups. We also found distinct morphological features and neurochemical properties between the labeled interneurons in layer I and other layers. These findings suggest that the laminar fate of LGE/CGE-derived interneurons depends on their spatial origin.

\section{Materials and Methods}

Animals. The mice used in the present study have been described previously (Torigoe et al., 2015). All experiments involving mouse care, sur- gery, and sample preparation were approved by the Animal Experimental Committee of Osaka University Graduate School of Frontier Biosciences and performed in accordance with the National Institutes of Health guidelines and the Osaka University Guidelines for the Welfare and Use of Laboratory Animals.

IUE. The methods for IUE have been described previously (Torigoe et al., 2015). In brief, IUE was performed on E10.5 in wild-type, Ai9, or Nxk2.1 ${ }^{\mathrm{Cre}}$; Ai9 mice of either sex. The cathode of tweezer type electrodes was positioned near the dorsal midline. To label all progenitor descendants, the Tol-2 system (Kawakami et al., 2004a, 2004b) and a Cre reporter line were used. pCAGGS -Tol2 transposase (T2TP) and pT2K-CAGGS-enhanced green fluorescent protein (EGFP) were coelectroporated with $p C A G G S$-tandem dimer tomato (tdTomato) or monomeric cherry (mCherry) to wild-type embryos. $p T 2 K$ CAGGS-EGFP is a Tol2 transposon-flanked EGFP and $p C A G G S-T 2 T P$ codes for Tol2 transposase. Upon the co-introduction of $p T 2 K-C A G G S$ EGFP and $p C A G G S-T 2 T P$ into a cell, the resulting transposon construct is excised from the plasmid and integrated into the host genome. For Ai9 mouse embryos, $p C A G G S$-Cre was electroporated with $p C A G G S$-EGFP to induce recombination of the genomic DNA in progenitor cells. To simultaneously label descendants of $N k \times 2.1^{+}$and $N k \times 2.1^{-}$progenitors in the same animal, $p C A G G S-T 2 T P$ and $p T 2 K-C A G G S-E G F P$ were electroporated to Nkx2.1 ${ }^{\mathrm{Cre}}$; Ai9 mice.

Preparation of tissue sections and immunohistochemistry. The methods for preparing tissue sections and immunohistochemistry have been described previously (Torigoe et al., 2015). The following primary antibodies (Abs) were used: rabbit polyclonal anti-DsRed Ab (1:300-500, 632496; Clontech), rabbit polyclonal anti-GABA Ab (1:2000, A2052; Sigma-Aldrich), chicken polyclonal anti-GFP Ab (1:1000, ab13970; Abcam), rat monoclonal anti-GFP Ab (1:1000, 04404-84; Nacalai Tesque), rabbit polyclonal anti-NPY Ab (1: 2000, 22940; Immunostar), sheep polyclonal anti-NPY Ab (1:2000, AB1583; Millipore), mouse monoclonal anti-PV Ab (1:1500, 235; Swant), mouse monoclonal anti-RLN Ab (1:1000, MAB5364; Millipore), goat polyclonal anti-SP8 Ab (1:500, sc104661; Santa Cruz Biotechnology), rat polyclonal anti-SST Ab (1:200, MAB354; Millipore), rabbit polyclonal anti-SOX6 Ab (1:2000, ab30455; Abcam), and rabbit polyclonal anti-VIP Ab (1:1000-5000, 20077; Immunostar). For SP8 and SOX6 immunostaining, sections were incubated with $2 \mathrm{~N} \mathrm{HCl}$ for $30 \mathrm{~min}$ at $37^{\circ} \mathrm{C}$ before application of the primary $\mathrm{Ab}$. The sections were then washed with $0.1 \mathrm{~m}$ borate buffer, $\mathrm{pH} 9.0$, for $10 \mathrm{~min}$.

The secondary Abs used were Alexa Fluor 488-conjugated donkey antichicken IgY (1:500, 703-545-155; Jackson ImmunoResearch), Alexa Fluor 488-conjugated goat anti-chicken IgY (1:500, 103-545-155; Jackson ImmunoResearch), Alexa Fluor 488-conjugated donkey anti-rat IgG (1:500, A21208; Life Technologies), Alexa Flour 594-conjugated goat anti-rabbit $\operatorname{IgG}(1: 1000$, A11012; Invitrogen), Alexa Fluor 647-conjugated donkey antirabbit IgG (1:500, A31573; Life Technologies), Alexa Fluor 647-conjugated goat anti-rat IgG (1:500, A21247; Invitrogen), Cyanine 3 (Cy3)-conjugated donkey anti-mouse IgG (1:500, 715-166-151; Jackson ImmunoResearch), Cy3-conjugated donkey anti-rabbit IgG (1:500, 711-165-152; Jackson ImmunoResearch), Cy3-conjugated goat anti-rat IgG (1:500, 612-104-120; Rockland Immunochemicals), and Cy5-conjugated donkey anti-mouse IgG (1:500, 715-175-150; Jackson ImmunoResearch).

Sampling and quantification. Five coronal sections at $500 \mu \mathrm{m}$ intervals were subjected to quantitative analysis. Serial sections were cut coronally at $50 \mu \mathrm{m}$ and sections were sampled at every 10 sections. Typically, the second rostralmost section included the anterior commissure and the caudalmost section included the lateral and basolateral amygdala. In some animals, sections at the level of the olfactory bulb were also analyzed to determine whether olfactory granule cells were labeled.

To quantify the laminar distribution of labeled cells, $500-\mu \mathrm{m}$-wide columnar regions spanning from the pial surface to the border with the white matter were located on the neocortex. For each section, 4 nonoverlapping columns were set so that the medial end of the medialmost column was located at $1.5-2.0 \mathrm{~mm}$ lateral from the midline. Therefore, a total of 20 columnar regions were selected for each animal. To assess the laminar distribution of the labeled cells, the column was divided into 10 tangential bins and the labeled cells in each bin were counted. In some animals, ToPro3 nuclear staining (1:500 in PBS, T3605; ThermoFisher) was performed to correlate the bin number with the cortical layers. We 

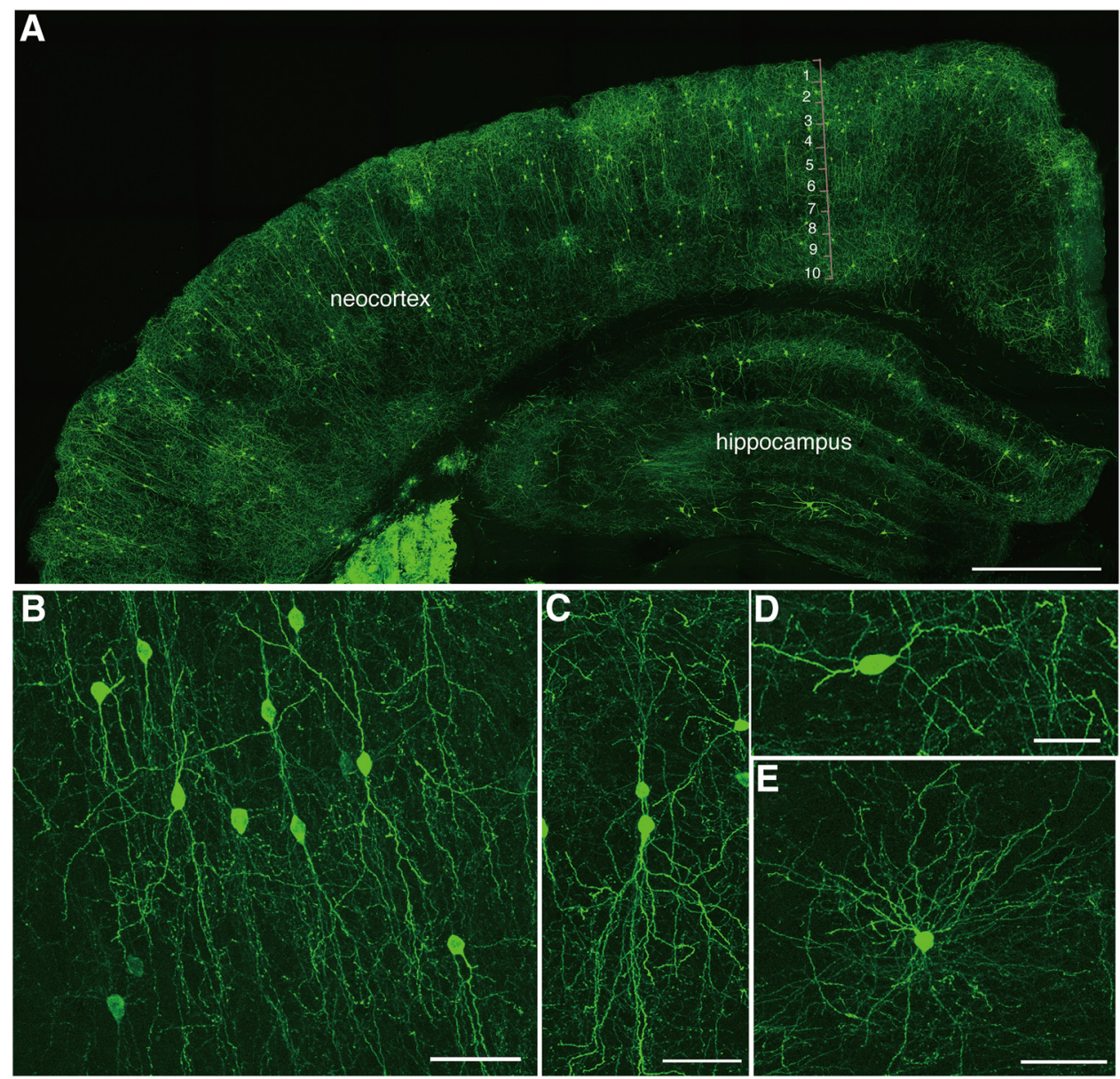

$\mathbf{F}$

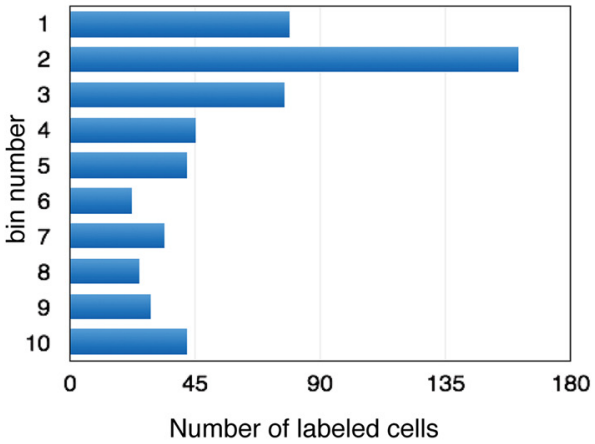

G

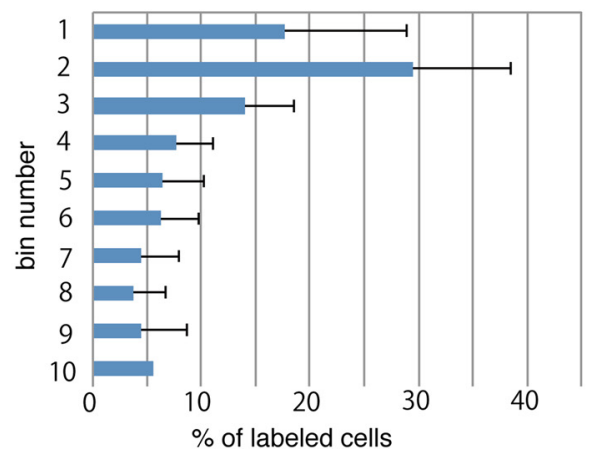

Figure 1. Neocortical interneurons labeled by IUE. $A$, Low-magnification view of the labeled neocortex. Neurons in the upper layers are labeled preferentially. $B, C$, Many neurons with radially oriented processes were labeled. Neurons with horizontally oriented cell bodies $(\boldsymbol{D})$ and multipolar shapes $(\boldsymbol{E})$ were also labeled. $\boldsymbol{F}$, Laminar distribution of the labeled cells shown in $\boldsymbol{A}$. The cortical wall was subdivided into 10 equal bins $(\boldsymbol{A})$ and the number of interneurons in each bin was counted. $\boldsymbol{G}$, Laminar distribution of IUE-labeled cells analyzed in this study (56 animals). A majority of labeled cells are localized in the upper cortical wall. The digits in the ordinate represent bin number and the abscissa indicates the proportion of labeled cells in each bin. Error bars indicate SD. Scale bars: $A, 500 \mu \mathrm{m} ; \boldsymbol{B}, \boldsymbol{C}, \boldsymbol{E}, 50 \mu \mathrm{m} ; \boldsymbol{D}, 30 \mu \mathrm{m}$.

compared the relationship between cortical layers and bin numbers in all 20 columns. Although the relationship varied depending on the cortical area, we found that bin 1 generally corresponded to layer I, or the marginal zone, and bins 2-4 mostly to layers II/III. In some regions, bin 4 included the upper half of layer IV, but a relatively small number of interneurons were generally labeled in this bin. Therefore, interneurons labeled in bin 1 will be referred to as layer I interneurons and those in bins 2-4 will be referred to as layers II/III interneurons.

Image processing. Image acquisition and processing were performed as described previously (Torigoe et al., 2015).

Classification of labeled cells. Labeled cells were classified based on their morphology. Those that extended at least one radial, straight process basally, apically, or both basally and apically across a length exceeding $100 \mu \mathrm{m}$ from the cell body and lacked processes extending in other directions from the cell body were termed radial cells. Those that lacked radial processes but extended multiple $(>3)$ processes in other directions were termed multipolar cells.

\section{Results}

Superficial distribution of labeled cells

All IUE experiments were done using embryos before the onset of neocortical interneuron neurogenesis at E10.5 (Fairén et al., 1986). IUE of a mixture of $p C A G G S-T 2 T P$ and $p T 2 K-C A G G S$ - 

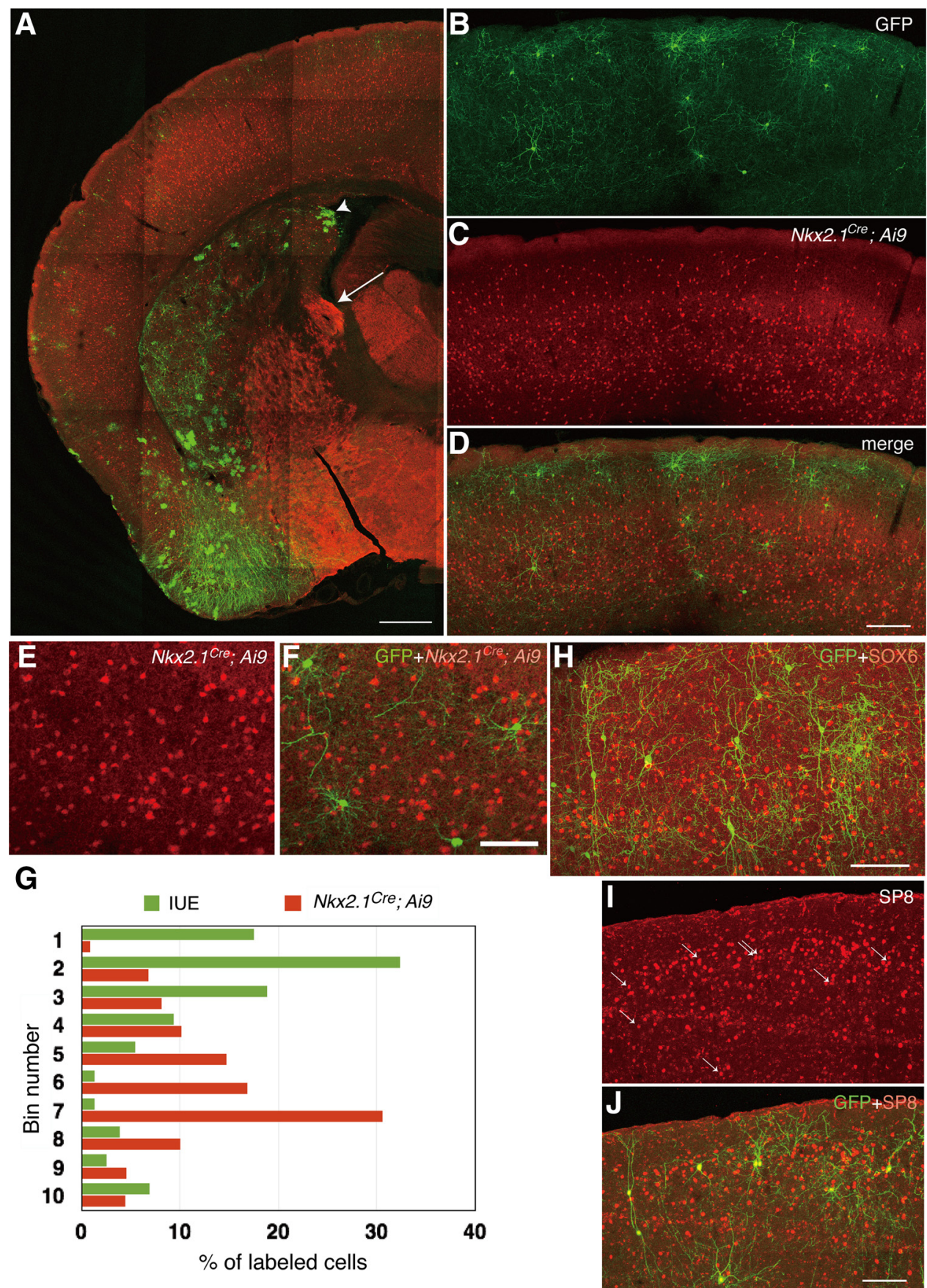

Figure 2. Extra-MGE/POA origin of IUE-labeled neocortical interneurons. $\boldsymbol{A}-\boldsymbol{F}$, IUE was performed on an Nkx2. $1^{\text {Cre }}$; Ai9 mouse. $\boldsymbol{A}$, Low-magnification view of an IUE-labeled mouse. Note that, whereas a remnant of $N k x 2.1$ activity occurs in the ventral ventricular zone of the lateral ventricle (arrow), an EGFP signal can be seen at the ventricular surface in the dorsolateral corner of the lateral ventricle (arrowhead). $\boldsymbol{B}$ - $\boldsymbol{C}$, Laminar distribution of IUE-labeled interneurons ( $\boldsymbol{B}$ ) and Nkx2.7 fate-mapped cells ( $\boldsymbol{C}$ ) show IUE-labeled interneurons are more superficially distributed (D). $\boldsymbol{D}$, Merged view of $\boldsymbol{B}$ and $\boldsymbol{C}$. $\boldsymbol{E}, \boldsymbol{F}$, Highermagnification view of $N k x 2.1$ fate-mapped cells (red) and IUE-labeled cells (green). There is no overlap of green and red signals. G, Laminar distribution of $N k x 2.1$ fate-mapped cells (red bars) and IUE-labeled cells (green bars) in the animal shown in $\boldsymbol{A}-\boldsymbol{F}$. Although $N k \times 2.7$ fate-mapped cells are localized preferentially to the deep zone $(n=4225$ cells), IUE-labeled cells are localized preferentially to the upper layers $(n=$ 74). $\boldsymbol{H}$, IUE-labeled cells in a wild-type animal were immunostained for SOX6. No IUE-labeled cell expresses SOX6. I, J, IUE-labeled interneurons express SP8, a LGE/CGE marker. $I$, SP8 expression. J, Merged view of IUE-labeled interneurons and SP8 immunoreactivity. The positions of IUE-labeled interneurons are indicated by arrows in I. Scale bars: $\boldsymbol{A}, 500 \mu \mathrm{m} ; \boldsymbol{D}, 200 \mu \mathrm{m} ; \boldsymbol{F}, J, 50 \mu \mathrm{m} ; \boldsymbol{H}, 100 \mu \mathrm{m}$.

EGFP enabled us to label persistently descendants originated from the progenitors that had incorporated these constructs, as reported previously (Yoshida et al., 2010; Kita et al., 2013). Therefore, IUE of these constructs to the subpallium labels neocortical GABAergic interneurons originating from labeled progenitors regardless of birthdate (Fig. 1A; Torigoe et al., 2015). The laminar distribution of labeled interneurons varied from animal to animal. The morphology of individual interneurons also varied, with some interneurons extending radially oriented processes (Fig. $1 B, C$ ) and others extending processes tangentially (Fig. $1 D$ ) or in many directions (Fig. 1E).

An analysis of the laminar distribution, however, indicated that a major population of labeled neurons tended to localize to the superficial laminae of the neocortex, in particular layers I-II/ III (bins 1-4), in most animals (Fig. 1A,F,G). Among the 7124 cells analyzed in 56 well stained animals, $>70 \%$ of labeled cells 


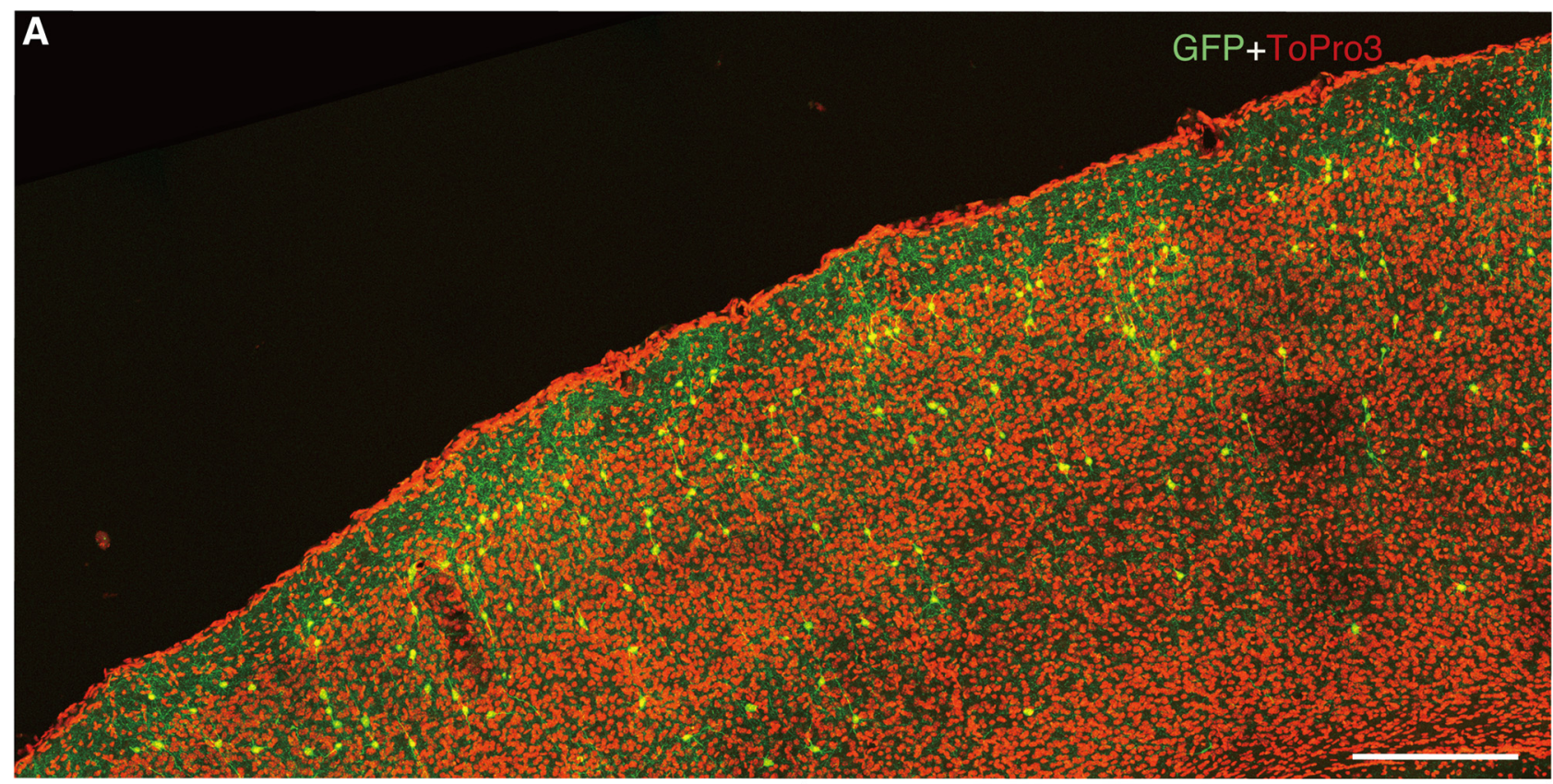

B

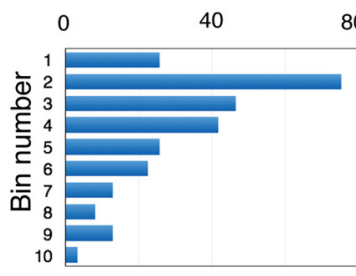

Number of labeled cells

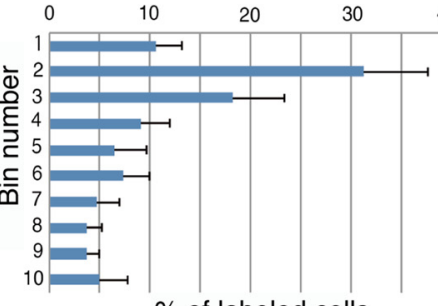

$\%$ of labeled cells
D 40

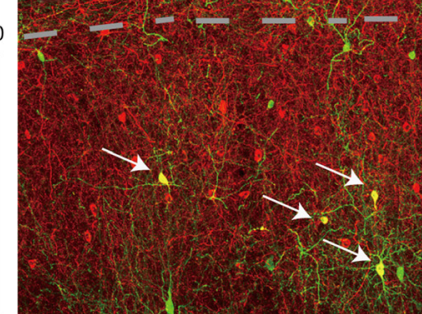

GFP+NPY

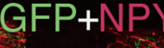

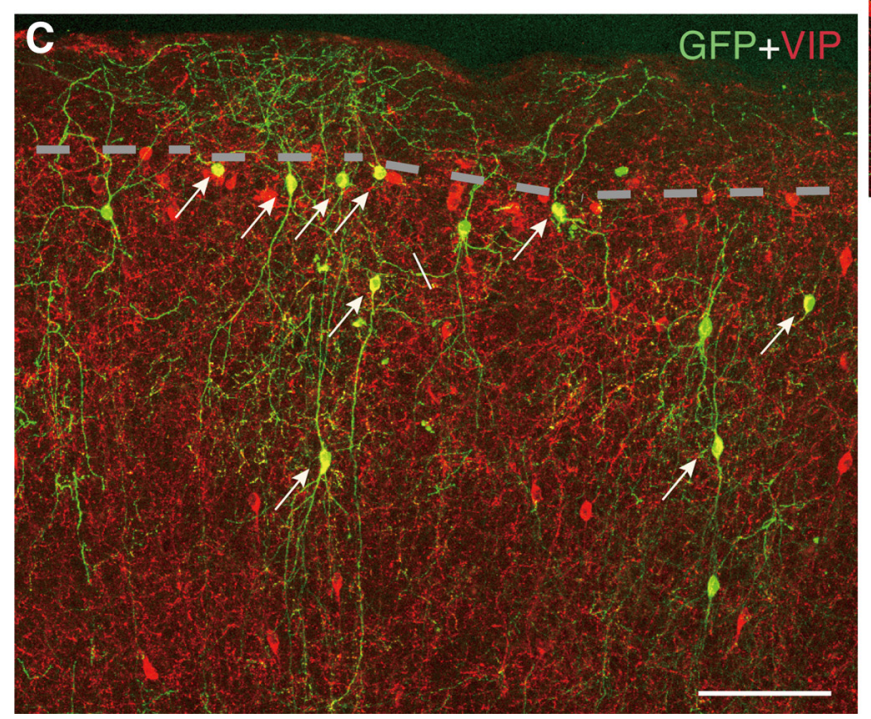

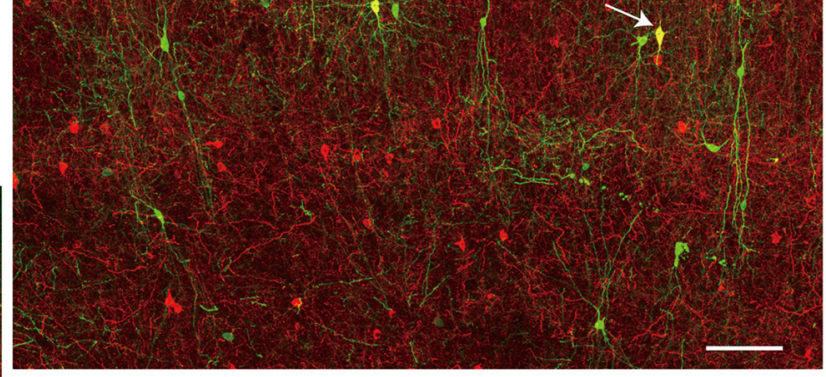

Figure 3. Preferential labeling of interneurons in upper layers other than layer l in a Group 1 animal. $\boldsymbol{A}$, Distribution of labeled interneurons in the neocortex. Labeled interneurons are preferentially localized in the upper layers, but layer I is almost devoid of labeled cells. The section was counterstained with ToPro3 (pseudocolored red). The graph on the left of $\boldsymbol{B}$ shows the laminar distribution of the interneurons in the animal shown in $A$ and that on the right shows the average distribution of 16 animals in which the number of labeled cells in bin 1 was $<1 / 3$ those in bin 2 . Ordinate indicates bin number. Abscissa indicate the proportion of labeled cells. Error bars indicate SD. C, IUE-labeled cells (green) and vasoactive intestinal peptide (VIP) immunoreactivity (red) in the same section show many VIP ${ }^{+}$IUE-labeled interneurons (arrows) in the lamina below layer I. The dashed line represents the approximate border of layer I and layers II/III. D, Similar to C but for an NPY-immunostained preparation. IUE-labeled interneurons (green) immunoreactive for NPY (red; arrows) are seen below layer I (yellow). Scale bars: $A, 500 \mu \mathrm{m} ; C, D, 100 \mu \mathrm{m}$. 

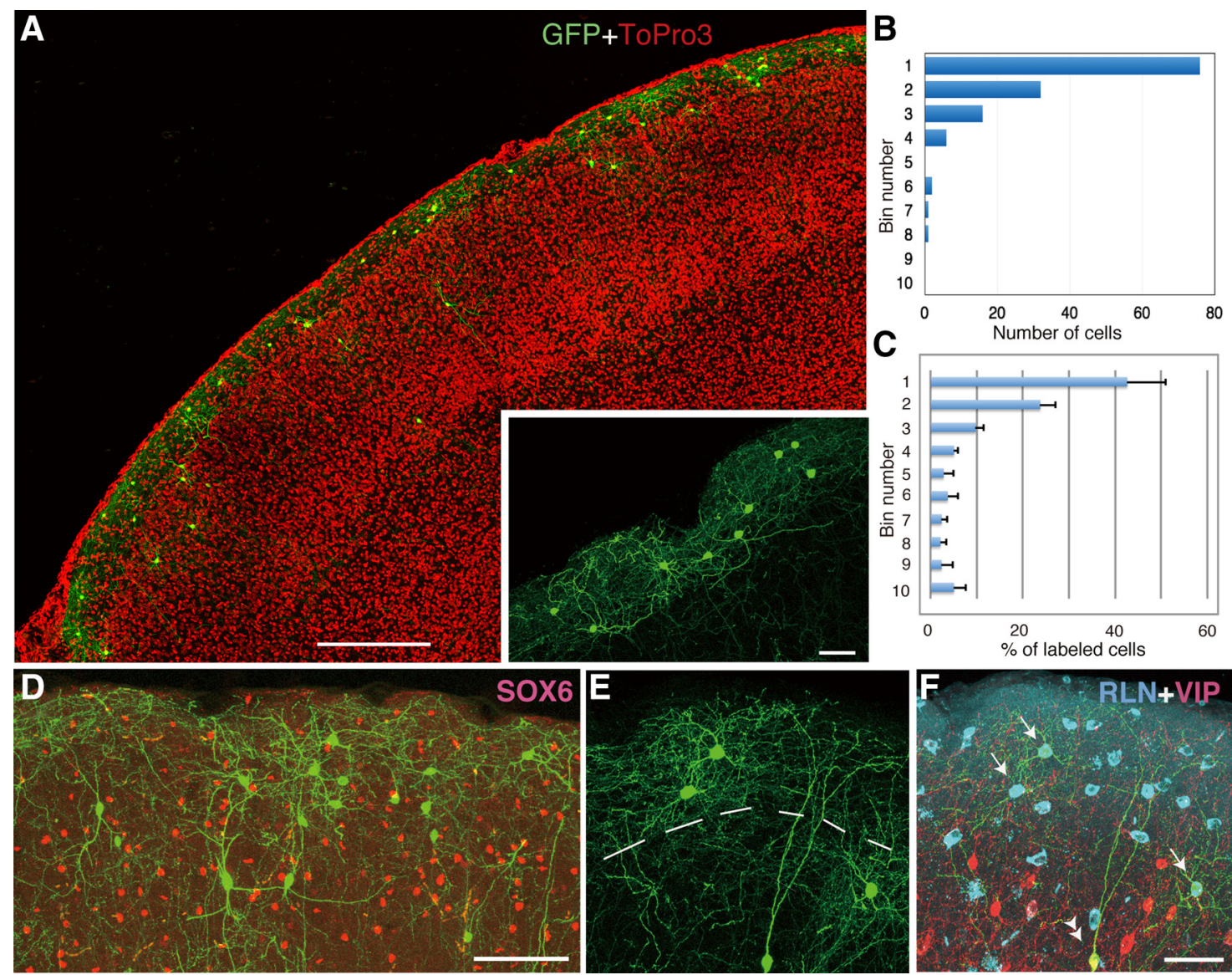

Figure 4. Preferential labeling of layer I neocortical interneurons in a Group 2 animal. $A$, Low-magnification view of IUE-labeled interneurons in the neocortex. Counter-stained with ToPro3 (pseudocolored red). Inset shows a high-magnification view of layer I interneurons. Interneurons with horizontally oriented processes are labeled. $\boldsymbol{B}$, Laminar distribution of interneurons in the animal shown in $\boldsymbol{A}$. $\boldsymbol{C}$, Average laminar distribution of interneurons in animals in which bin 1 interneurons outnumber the other bins $(n=5)$. Error bars indicate SD. $\boldsymbol{D}$, IUE-labeled neurons in Group 2 (green) do not express SOX6 (red). SOX6 immunostaining was performed on an IUE-labeled section. $\boldsymbol{E}, \boldsymbol{F}$, Expression of RLN and VIP in IUE-labeled cells (green) of a Group 2 animal. Double immunostaining against RLN (blue) and VIP (red). IUE-labeled cells were stained for RLN (arrows) or VIP (double arrowhead). The dashed line in $\boldsymbol{E}$ shows the approximate border of layer I and layers II/III. Note that two layer I interneurons near the upper left corner express RLN. Scale bars: $A, 300 \mu \mathrm{m} ; \boldsymbol{A}$ inset, $50 \mu \mathrm{m} ; \mathbf{D}, 100 \mu \mathrm{m} ; \boldsymbol{F}, 50 \mu \mathrm{m}$.

were localized to layers I-II/III in 32 animals and $>60 \%$ in 46 animals. In the remaining 10 animals, the proportion of cells in layers I-II/III ranged from $30 \%$ to $56 \%$.

Given that CGE-derived interneurons are preferentially localized to the upper layers (Xu et al., 2004; Butt et al., 2005; Lee et al., 2010; Miyoshi et al., 2010; Rubin et al., 2010; Vucurovic et al., 2010; Ma et al., 2012), the present results raise the possibility that CGE progenitors were preferentially labeled. This interpretation is consistent with our previous analysis of IUE-labeled sites in embryos, in which the LGE and CGE tended to be preferentially labeled (Torigoe et al., 2015).

\section{LGE/CGE origin of IUE-labeled interneurons}

More than $70 \%$ of labeled cells fate-mapped by Mash $1 B A C^{\text {CreER }}$, which causes specific reporter gene expression in the LGE/CGE, are localized to layers I and II/III regardless of the time of tamoxifen administration (Miyoshi et al., 2010). This localization suggests that the IUE performed in the 32 animals in which $>70 \%$ of labeled cells were localized to layers I-II/III was largely targeted to the LGE/CGE. We therefore focused on these 32 animals in this study.

Several lines of evidence indicate that the IUE-labeled interneurons in these samples are indeed of extra-MGE/POA origin. First, a previous study showed that $N k \times 2.1$ expression persisted into the first postnatal week at the ventricular zone of the lateral ventricle, likely a remnant or extension of the MGE/ POA (Taniguchi et al., 2013). In Nkx2.1 ${ }^{\mathrm{Cre}}$; Ai9 mice with IUE of EGFP (Fig. 2A), we observed a similar remnant of EGFP-labeled cells in the ventricular zone of the lateral ventricle (Fig. $2 A$, arrowhead; see also Fig. $5 A$ ) at sites more dorsal than tdTomato expression, a remnant or extension of the MGE/POA (Fig. $2 A$, arrow). Further, in these Nkx2.1 ${ }^{\mathrm{Cre}}$; Ai9 mice, no EGFP-labeled cells expressed tdTomato ( $0 \%, 248$ cells, 4 animals; Fig. $2 B-F)$. In addition, IUE-labeled interneurons displayed a laminar distribution distinct from those of $N k \times 2.1$ fate-mapped interneurons (Fig. 2G). Although most of the MGE region and the POA express Nkx2.1, the expression of Cre recombinase is weak in the dorsal part of the MGE in the Nkx2.1 ${ }^{\mathrm{Cre}}$ mice used in this study (Xu et al., 2008). Therefore, IUE-labeled cells, if originated from the dorsal MGE, might not express tdTomato. To test this possibility, we performed immunostaining for SST by taking advantage of the fact that the dorsal MGE generates $\mathrm{SST}^{+}$interneurons (Gelman and Marín, 2010). We found that almost no IUE-labeled cells were $\mathrm{SST}^{+}(2.1 \%, 467$ cells, 5 animals), supporting the conclusion that the vast majority of IUE-labeled interneurons in $\mathrm{Nk} \times 2.1^{\mathrm{Cre}}$; Ai9 mice are of extra-MGE/POA origin.

In wild-type animals, we performed immunostaining against SOX6, a molecule specifically expressed in mature MGE-derived interneurons (Batista-Brito et al., 2009). We found that only a small fraction of IUE-labeled cells $(3.8 \%, 523$ cells, 6 animals) 
Table 1. Summary of labeled sites in Group 1 and 2 animals

\begin{tabular}{|c|c|c|c|c|c|c|c|c|c|c|c|c|c|c|c|c|}
\hline Group 1 & & & & & & & & & & & & & & & & \\
\hline Animal \# & 1 & 2 & 3 & 4 & 5 & 6 & 7 & 8 & 9 & 10 & 11 & 12 & 13 & 14 & 15 & 16 \\
\hline \multicolumn{17}{|l|}{ Labeled site } \\
\hline Rostral striatum & 0 & 0 & $\bigcirc$ & 0 & 0 & 0 & 0 & $\triangle$ & $\times$ & $\triangle$ & $\bigcirc$ & $\bigcirc$ & $\bigcirc$ & $\bigcirc$ & $\bigcirc$ & $\triangle$ \\
\hline Striatum & $\bigcirc$ & $\bigcirc$ & $\bigcirc$ & $\bigcirc$ & ○ & ○ & $\bigcirc$ & $\triangle$ & $\triangle$ & $\triangle$ & $\bigcirc$ & $\bigcirc$ & ○ & $\bigcirc$ & ○ & $\bigcirc$ \\
\hline Nucleus accumbens & $\bigcirc$ & 0 & $\bigcirc$ & 0 & 0 & 0 & $\bigcirc$ & $\triangle$ & $\times$ & $\triangle$ & $\bigcirc$ & $\bigcirc$ & $\bigcirc$ & $\bigcirc$ & $\bigcirc$ & $x$ \\
\hline Basolateral amygdala & $x$ & $x$ & $x$ & $x$ & $x$ & $x$ & $x$ & $x$ & $x$ & $x$ & $x$ & $x$ & $x$ & $x$ & $x$ & $x$ \\
\hline Lateral amygdala & $\triangle$ & 0 & $\bigcirc$ & $\bigcirc$ & 0 & $\bigcirc$ & $\times$ & $\bigcirc$ & 0 & $x$ & $\bigcirc$ & 0 & $x$ & $\times$ & $x$ & $\triangle$ \\
\hline Intercalated cell mass & 0 & 0 & $\bigcirc$ & $\bigcirc$ & 0 & $\bigcirc$ & $\triangle$ & $x$ & $\times$ & $x$ & 0 & 0 & $\bigcirc$ & $\bigcirc$ & $\triangle$ & $x$ \\
\hline Central amygdala & 0 & $\bigcirc$ & $\times$ & $\bigcirc$ & $x$ & $\bigcirc$ & $\triangle$ & $x$ & $x$ & $\triangle$ & & $x$ & $\bigcirc$ & $\bigcirc$ & $\triangle$ & $x$ \\
\hline Hypothalamus & $x$ & $x$ & $\times$ & $\triangle$ & $\triangle$ & $x$ & $\times$ & $x$ & $\triangle$ & $x$ & $\triangle$ & $x$ & $x$ & $\times$ & $x$ & $\times$ \\
\hline Granule cells in olfactory bulb & NA & NA & NA & NA & NA & NA & $\bigcirc$ & NA & NA & $\bigcirc$ & NA & NA & NA & $\bigcirc$ & $\bigcirc$ & $\bigcirc$ \\
\hline $\operatorname{bin} 1 /$ bin2-4 & 0.16 & 0.2 & 0.07 & 0.18 & 0.23 & 0.3 & 0.16 & 0.23 & 0.19 & 0.28 & 0.25 & 0.29 & 0.15 & 0.3 & 0.26 & 0.12 \\
\hline bin $1 / 2$ & 0.34 & 0.53 & 0.13 & 0.36 & 0.37 & 0.43 & 0.29 & 0.43 & 0.27 & 0.47 & 0.49 & 0.52 & 0.35 & 0.38 & 0.48 & 0.22 \\
\hline
\end{tabular}

Group 2

\begin{tabular}{lllllll}
\hline Animal \# & 17 & 18 & 19 & 20 & 21 \\
\hline Labeled site & $\times$ & $\times$ & $\times$ & $\times$ & $\times$ \\
$\quad$ Rostral striatum & $\times$ & $\triangle$ & $\triangle$ & $\times$ & $\times$ \\
$\quad$ Striatum & $\times$ & $\times$ & $\times$ & $\times$ & $\times$ \\
Nucleus accumbens & $\bigcirc$ & $\triangle$ & $\bigcirc$ & $\triangle$ & $\bigcirc$ \\
Basolateral amygdala & $\bigcirc$ & $\triangle$ & $\bigcirc$ & $\bigcirc$ & $\bigcirc$ \\
Lateral amygdala & $\mathrm{NA}$ & $\bigcirc$ & $\triangle$ & $\times$ & $\times$ \\
Intercalated cell mass & $\mathrm{NA}$ & $\times$ & $\times$ & $\times$ & $\times$ \\
Central amygdala & $\mathrm{NA}$ & $\bigcirc$ & $\bigcirc$ & $\bigcirc$ & $\bigcirc$ \\
Hypothalamus & $\times$ & $\times$ & $\times$ & $\times$ & $\mathrm{NA}$ \\
Granule cells in olfactory bulb & $\times$ & \\
Bin1/bin2-4 & 0.92 & 1.3 & 0.81 & 1.41 & 1.06 \\
Bin1/bin2 & 1.5 & 4.6 & 1.4 & 2.4 & 1.72 \\
\hline
\end{tabular}

Circles, triangles, and $\times$ 's indicate prominent labeling, sparse labeling and devoid or almost devoid of labeling, respectively. NA indicates that sections are unavailable. "Rostral striatum" indicates the striatal region rostral to the corpus callosum and "striatum" indicates the rest of the striatal region. "Bin1/bin2" and "bin1/bin $2-4$ " indicate the ratio of labeled cells within the indicated bins.

expressed SOX6 (Fig. 2H; also see Fig. 4D). MGE-derived interneurons express either PV or SST, depending on spatial domains of progenitors (Gelman and Marín, 2010). Therefore, we also tested the expression of these molecules in IUE-labeled interneurons using the same animals. Again, only a small fraction (1.6\%, 442 cells, 6 animals) expressed either of them, suggesting extra-MGE origin of the labeled interneurons. In two of these animals, in which no IUE-labeled interneurons expressed either PV or SST, we performed immnostaining for SP8, a transcription factor known to be expressed in a subpopulation of LGE/CGE-derived interneurons (Ma et al., 2012). We found that a majority of IUElabeled interneuron (74\%, 152 cells) expressed SP8 (Fig. 2 I, J), confirming the LGE/CGE origin of IUE-labeled interneurons.

Collectively, these findings suggest that the sites of IUE are largely restricted to the extra-MGE/POA region, namely LGE/ CGE, in the animals analyzed in this study.

Interneurons in upper layers other than layer I are predominantly labeled in a group of animals

Although upper layer interneurons tended to be labeled preferentially, we noticed that labeled interneurons in layer I were sparse compared with those in other upper layers in some animals (Fig. $3 A$ ). Given that our IUE method used in this study could label all descendants of labeled progenitors, this observation raises the possibility that there exists a PD that preferentially contributes to layers II/III interneurons. We found that the number of labeled cells in layer I was no more than $1 / 3$ of the total number of labeled interneurons in layers II/III in 16 of the 32 animals (Fig. $3 A, B$ ). We termed these animals Group 1 animals and subjected them to further analysis. In Group 1 animals, the zone near the cortical surface looked to be devoid of labeled cells at first glance (Fig. 3A). Many of them expressed VIP (Fig. 3C) or NPY (Fig. 3D; also see Fig. 6). The existence of Group 1 animals suggests that there are LGE/CGE PDs that preferentially contribute to layers II/III.

\section{Layer I interneurons are preferentially labeled in another set of animals}

The above results suggest that the layer I interneurons originate from a PD largely distinct from that for Group 1 animals. This led us to speculate that there must be animals in which layer I interneurons are labeled preferentially. Indeed, we found a group of animals for which interneurons labeled in bin 1 outnumbered those in other bins (5 animals; Fig. $4 A-C$, Table 1). We termed these animals Group 2 animals (laminar distribution of the remaining 11 animals showed a mixture of Group 1 and 2, with an abundance of labeled interneurons both in layer I and layers II/III). The occurrence of Group 2 animals suggests that there exists a PD that contributes preferentially to layer I interneurons. Collectively, the evidence presented thus far indicates that there are at least two distinct PDs that contribute preferentially to layer I or other upper layers (mainly layers II/III). The interneurons labeled in Group 2 animals were SOX6 $^{-}$(Fig. 4D), confirming the extra-MGE/POA origin of these cells. Many of the interneurons labeled in layer I expressed RLN but not VIP (Fig. 4E, F; also see Fig. 6).

It is unlikely that these layer I neurons are Cajal-Retzius cells, because those cells disappear during postnatal development (Teissier et al., 2010; Martinez-Galan et al., 2014) and RLN is expressed exclusively in GABAergic interneurons within the P21 neocortex (Miyoshi et al., 2010). Moreover, these neurons labeled in layer I expressed GABA or glutamate decarboxylase (GAD) (data not shown and Torigoe et al., 2015). 

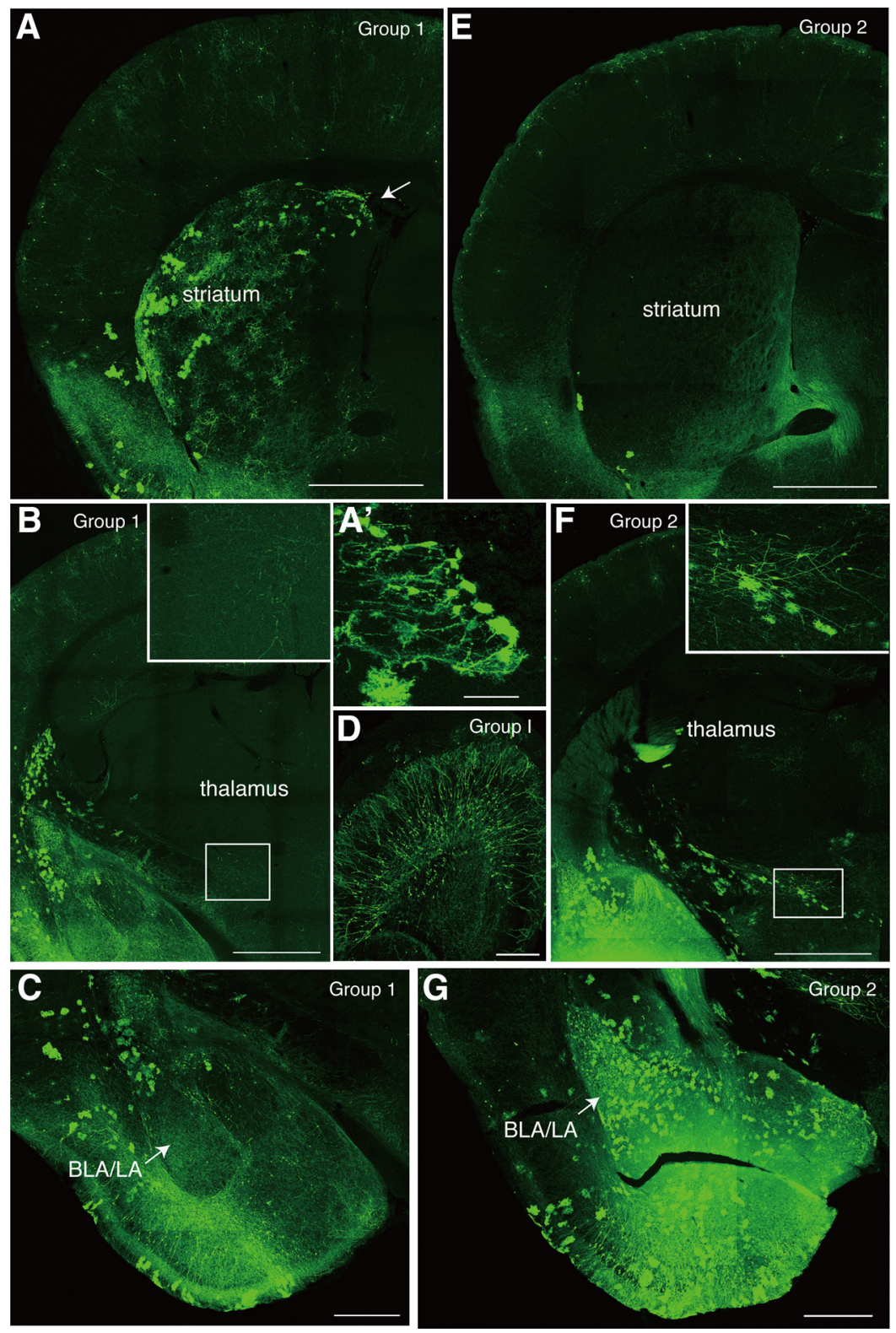

Figure 5. Labeled cells in subcortical structures in Group 1 and 2 animals. $\boldsymbol{A}-\boldsymbol{D}$, Labeled cells in Group 1 animals. $\boldsymbol{A}, \boldsymbol{B}$, Lowmagnification view at the level that includes the rostral striatum $(\boldsymbol{A})$ and the hypothalamus $(\boldsymbol{B})$. The striatum was densely labeled $(\boldsymbol{A})$, but no cells were labeled in the hypothalamus ( $\boldsymbol{B}$ and $\boldsymbol{B}$ inset). In these animals, cells facing the lateral ventricle were often observed at the dorsolateral corner, possibly a remnant of IUE-labeled progenitors (arrow in $\boldsymbol{A}$ ). An enlarged view is shown in $\boldsymbol{A}^{\prime}$. The BLA/LA were almost devoid of labeled cells, although axonal and dendritic processes of unidentified cells can be recognized ( $\boldsymbol{C}$, arrow). Olfactory granule cells were also labeled (D). $\boldsymbol{E}-\boldsymbol{G}$, Labeled cells in Group 2 animals. $\boldsymbol{E}$, Low-magnification view at the level that includes the rostral striatum. In the neocortex, interneurons near the cortical surface were predominantly labeled. Only a small number of cells were labeled in the striatum $(\boldsymbol{E})$. $\boldsymbol{F}$, At a more caudal level, cells were labeled in the hypothalamus ( $\boldsymbol{F}$ and $\boldsymbol{F}$ inset). $\boldsymbol{G}$, In the amygdala, the BLA/LA were labeled (arrow). Insets in $\boldsymbol{B}$ and $\boldsymbol{F}$ are high-magnification views of boxed areas in each. All panels show images of coronal sections. Scale bars: $\boldsymbol{A}, \boldsymbol{B}, \boldsymbol{E}, \boldsymbol{F}, 1 \mathrm{~mm} ; \boldsymbol{C}, \boldsymbol{G}, 500 \mu \mathrm{m} ; \boldsymbol{D}, 250 \mu \mathrm{m} ; \boldsymbol{A}^{\prime}, 50 \mu \mathrm{m}$.

\section{Distinct subcortical regions are labeled between the two groups of animals}

The evidence presented thus far raises the possibility that there are at least two distinct PDs within the LGE/CGE. Previously, we showed that PDs in the subpallium give rise to neurons and astrocytes in varying subcortical structures and that the labeled subcortical structures varied from animal to animal (Torigoe et al., 2015). We reasoned that we should be able to observe differences in the pattern of labeling in subcortical structures between Group 1 and 2 animals if the labeled PDs are indeed different.
To test this idea, we next examined the pattern of labeling in subcortical structures, finding profound differences (Table $1)$. In Group 1 animals, the striatum was heavily labeled (Fig. 5A). In contrast, in Group 2 animals, the striatum was only sparsely labeled. In particular, the rostral part of the striatum was almost devoid of labeled cells (Fig. 5E). In the hypothalamus of Group 2 animals, labeled cells were found (Fig. $5 F$ ), but almost no cells were labeled there in Group 1 (Fig. 5B). Furthermore, we found that granule cells in the olfactory bulb were labeled in Group 1 (Fig. 5D), but not in Group 2 animals (data not shown). Finally, we compared the labeling of the amygdala. Basolateral amygdala (BLA) was almost devoid of labeled cells, and lateral amygdala (LA) was labeled only in a subset of Group 1 animals (Fig. 5C, Table 1). In contrast, LA or both BLA and LA were labeled in all Group 2 animals (Fig. 5G). There were several differences in the pattern of the subcortical structure labeling between the two groups, lending support to the notion that labeled PDs in the LGE/CGE are different between Groups 1 and 2 .

\section{Differential expressions of} neurochemical markers between layer I and other layers

LGE/CGE-derived interneurons express several neurochemical markers including VIP, RLN, NPY, and calretinin (Lee et al., 2010; Miyoshi et al., 2010; Ma et al., 2012; Miyoshi et al., 2015). These molecules are expressed across all cortical layers. Interestingly, $\mathrm{RLN}^{+}$interneurons are strikingly predominant in layer I, whereas none of these neurochemical marker-expressing neurons stands out from others in other layers (Lee et al., 2010; Miyoshi et al., 2010; Ma et al., 2012). Analogous to the finding that there is a correlation between the expression of neurochemical markers in MGE-derived interneurons and their spatial origins (Gelman and Marín, 2010), these findings led us to speculate that these $\mathrm{RLN}^{+}$layer I interneurons are derived from a PD distinct from that of other layers.

We considered whether the PD for Group 2 animals, which preferentially generates layer I interneurons, may correspond to the one that generates the RLN-rich population of interneurons. If so, we would expect that IUE-labeled layer I interneurons in Group 2 animals should include a predominant proportion of $\mathrm{RLN}^{+}$interneurons. To explore this possibility, we examined the proportion of interneurons expressing these neurochemical markers in layer I. As expected, whereas $\sim 80 \%$ of layer I interneurons expressed RLN, only $<10 \%$ expressed VIP or NPY 
A 1.0

Layer I, Group 2



B Layers II/III-VI,Group 1

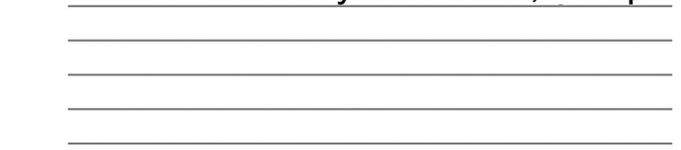

0.5



Figure 6. Proportion of neocortical interneurons expressing neurochemical markers. A, Proportion of layer I interneurons expressing RLN ( $n=3$ animals), VIP ( $n=2$ animals), or NPY ( $n=3$ animals) (all Group 2 animals). The expression of RLN is outstanding. $\boldsymbol{B}$, Proportion of layer II/III-VI interneurons expressing RLN ( 6 animals), VIP ( 6 animals) or NPY ( 4 animals) (all Group 1 animals). Comparable proportions of interneurons express each neurochemical marker. Error bars indicate SD.

(Fig. 6A). Taking into account of the fact that the interneuron populations labeled in Group 1 and Group 2 are largely complementary to each other, we expected that none of these neurochemical markers may be outstandingly expressed in interneurons labeled in layers II/III-VI of Group 1 animals (Lee et al., 2010). Indeed, we found comparable proportions ( $20 \%)$ of layers II/III-VI interneurons in Group 1 animals that expressed these three neurochemical markers (Fig. 6B).

Together with the findings shown in the previous sections, these results are consistent with the hypothesis that there is a PD that preferentially generates $\mathrm{RLN}^{+}$layer I interneurons and a separate $\mathrm{PD}$ that gives rise to a comparable proportion of $\mathrm{RLN}^{+}, \mathrm{NPY}^{+}$, and $\mathrm{VIP}^{+}$interneurons in other layers (mainly layers II/III).

\section{Variation of labeled neurons in layers II/III-VI}

We have provided evidence suggesting that there are at least two distinct PDs for neocortical interneurons within the LGE/CGE. We found that there was a variation in the morphology and molecular expression among labeled neurons in layers II/III-VI of Group 1 animals (Fig. 3C,D). Some of the neurons were $\mathrm{VIP}^{+}$ (Fig. $3 C$ ), whereas others were $\mathrm{NPY}^{+}$(Fig. 3D); in addition, some extended radially oriented processes (Fig. $1 B, C$ ), whereas others extended processes in multiple directions (Fig. 1E).

It is possible that a particular PD within the LGE/CGE generates molecularly and morphologically diverse types of interneurons. However, an alternative possibility is that there are subdomains generating specific types of interneurons. During the course of the analysis, we found that there was a variation in morphology, laminar distribution, and neurochemical marker expression within Group 1 animals. In some animals, labeled cells exhibiting radially oriented processes were conspicuous (Fig. $7 A$ ), whereas multipolar cells prevailed in others (Fig. $7 B$ ). Furthermore, we found that there was a correlation between neuronal morphology and neurochemical marker expressions. In the animal shown in Figure 7A, 56\% of radially oriented interneurons $(n=28 / 50)$, but only $13 \%$ of multipolar interneurons $(n=$ 17/134), were VIP ${ }^{+}$(Fig. 7C). Conversely, in the animal shown in Figure $7 B, 28 \%$ of multipolar interneurons $(n=24 / 85)$, but only $0.5 \%(1 / 21)$ of radially oriented interneurons were $\mathrm{NPY}^{+}$ (Fig. 7D). Similar results were obtained for four other VIPimmunostained and three other NPY-immunostained samples. We also found that, whereas interneurons with radial processes barely existed in bins 7-10, a comparable proportion of multipolar interneurons were distributed in bins $4-10$ (Fig. $7 E, F$ ). Notably, we found that the ratio of interneurons with radially oriented processes to multipolar cells varied from animal to animal (5-28\% among 12 animals, 2790 cells), a result that is hard to explain if we assume that both types of cells originate from a specific $P D$. Therefore, these findings are consistent with the view that distinct sub-PDs within the labeled PD in Group 1 animals generate interneurons with characteristic morphologies, expression of neurochemical markers, and laminar distribution.

\section{Discussion}

In the mammalian CNS, the birthdate of neurons is the major determinant of their laminar fate. In the neocortex, for example, late-born excitatory neurons migrate radially past early-born neurons to settle in more superficial layers, forming an inside-out gradient of neurogenesis (Angevine and Sidman, 1961). Curiously, despite the difference in migratory patterns, MGE-derived neocortical interneurons, which reach the cortical plate after long-distance tangential migration followed by radial migration (Tanaka et al., 2003, 2006, 2009), also populate the cortex in an inside-out manner depending on their birthdate (Miller, 1985; Fairén et al., 1986; Valcanis and Tan, 2003; Miyoshi et al., 2007; Rymar and Sadikot, 2007). Other neurons, such as those in the superior colliculus (Altman and Bayer, 1981), retina (Cepko et al., 1996) and the pontine nucleus (Altman and Bayer, 1987; Shinohara et al., 2013), also form laminar structures in a birthdate-dependent manner. In contrast, the laminar fate of LGE/CGE-derived interneurons appears to be largely independent of their birth (Cavanagh and Parnavelas, 1989; Miyoshi et al., 2011). The present study showed that their laminar fate instead depends on the site of their generation.

\section{Methodological considerations}

The IUE method used in this study should not allow us to label progenitors in specific PDs in a controlled manner, thus giving rise to labeling patterns of the cortical layers and subcortical structures that vary from animal to animal (Torigoe et al., 2015). However, it was possible to classify labeled samples based on the pattern of labeling. Examination of the laminar distribution of labeled interneurons in the neocortex, together with the pattern of labeling in subcortical structures, led us to infer retrospectively the PDs targeted by IUE.

It is unlikely that the difference in the laminar distribution between Group 1 and 2 animals reflects differences in neuronal birthdate, because the Tol-2 system used here in principle labels interneurons originated from labeled PDs regardless of birthdate. Therefore, it is likely that the variation in labeling patterns observed in this study reflects the variation of PDs labeled by IUE.

The reason that extra-MGE/POA PDs were targeted preferentially in this study is unknown. One explanation is the technical 

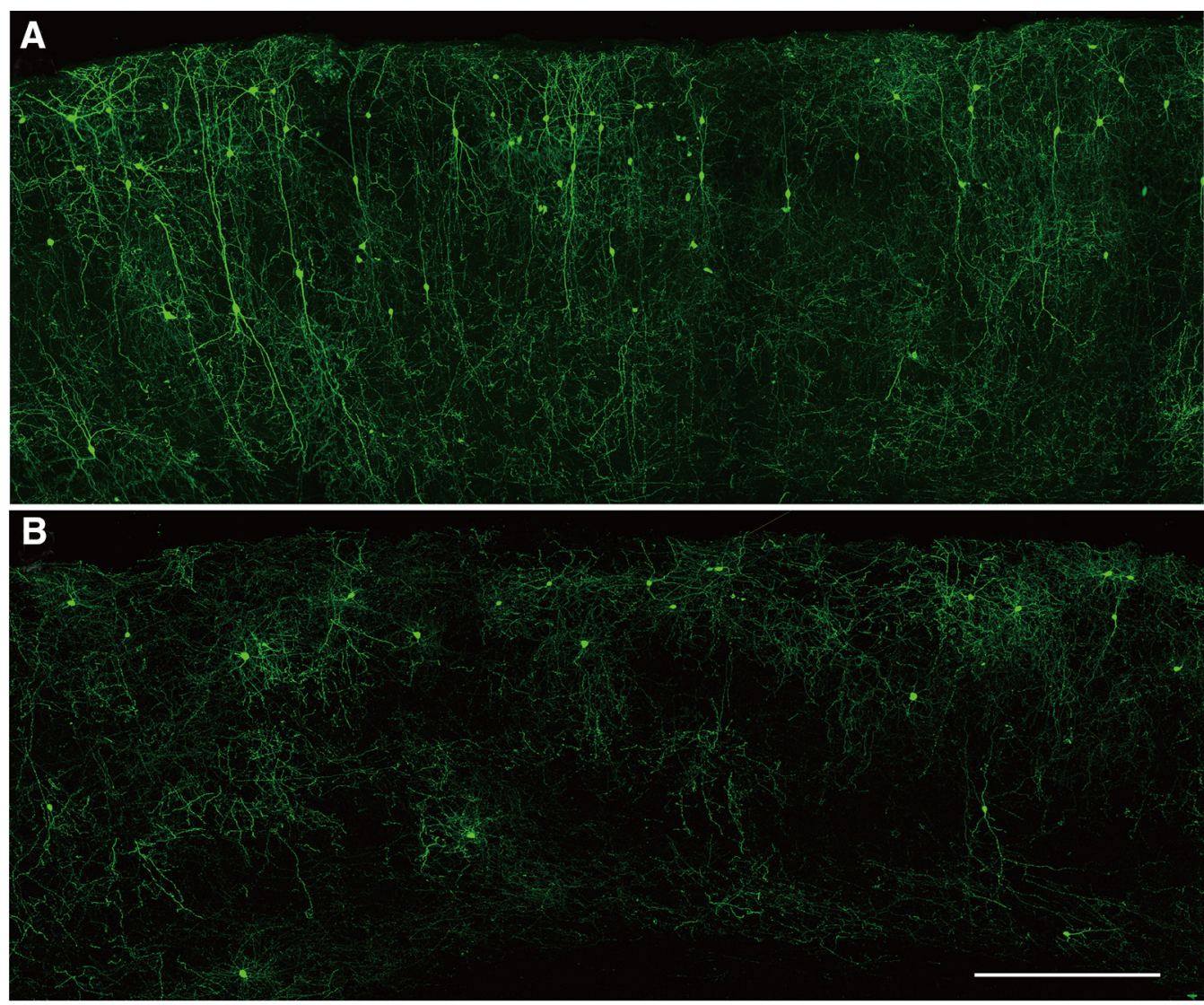

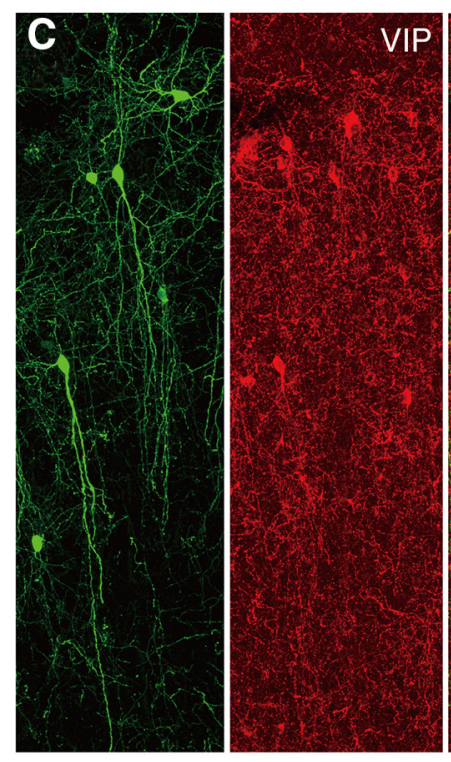

E Radial

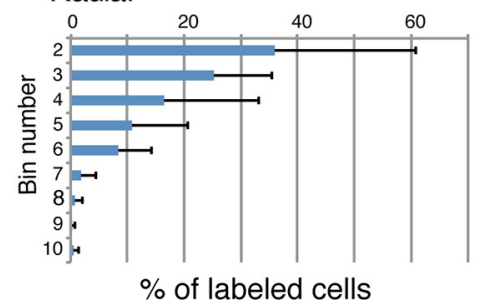

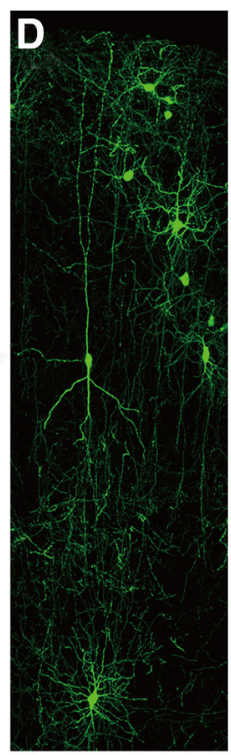

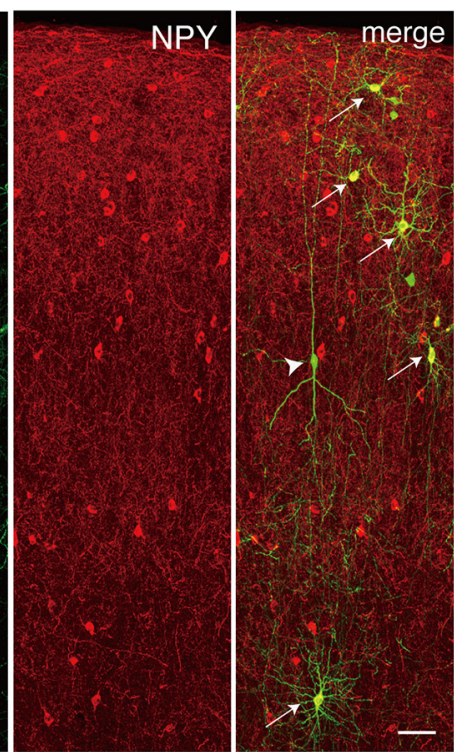

F Multipolar

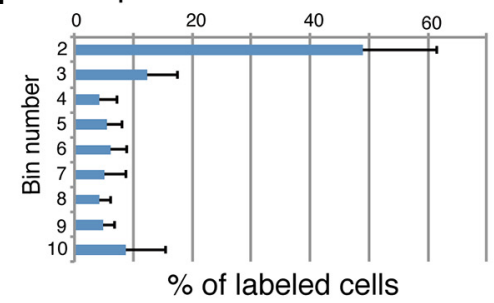

Figure 7. Diversity of labeled interneurons in layers II-VI in Group 1 animals. $\boldsymbol{A}, \boldsymbol{B}$, Two types of labeled interneurons with distinct morphological features. In some Group 1 animals, interneurons having radially extending processes were prominent $(\boldsymbol{A})$, whereas those with multipolar interneurons were dominant in others $(\boldsymbol{B})$. $\boldsymbol{C}$, IUE-labeled interneurons (left) immunostained for VIP (middle). In the merged view shown on the right, VIP ${ }^{+}$interneurons with radially oriented processes are indicated by arrows, whereas a VIP ${ }^{-}$interneuron with multipolar shape is indicated by an arrowhead. D, IUE-labeled interneurons (left) immunostained for NPY (middle). In the merged view shown on the right, NPY ${ }^{+}$interneurons with multipolar shape (Figure legend continues.) 


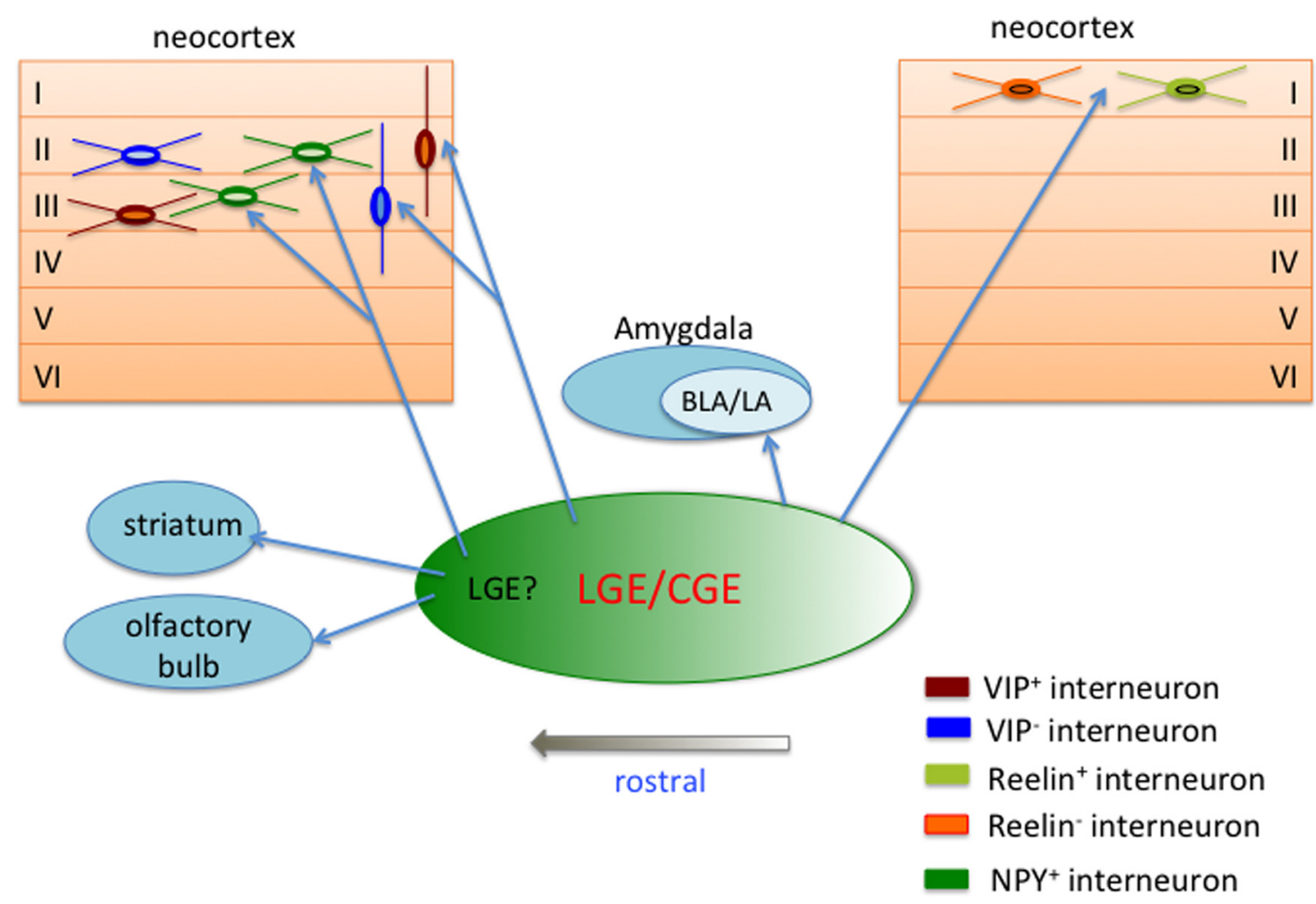

Figure 8. Summary diagram showing that distinct PDs within the LGE/CGE generate subsets of neocortical interneurons with distinct laminar distribution and molecular and morphological characteristics. Progenitors possibly located within the LGE and/or rostral part of the CGE give rise to interneurons mainly in layers II/III. A subset of the interneurons express VIP and are radially oriented. NPY-expressing neurons are also generated. The same PD or a PD nearby may give rise to striatal cells and olfactory granule cells. Progenitors possibly located within the caudal part of the CGE give rise to interneurons in layer I. These interneurons, which exhibit multipolar shapes or horizontally oriented processes, express RLN. The same PD or a PD nearby may also give rise to the BLA/LA of the amygdala. Interneurons with radially oriented processes and multipolar cells might originate from distinct sub-PDs located within the PD that generates layers II/III interneurons.

difficultly of targeting electrodes to the MGE/POA region, which is located at the ventral bottom of the neural tube at E10.5, whereas LGE/CGE is located in the lateral wall and is more easily accessible. It seems unlikely that the constructs used in this study operated preferentially in LGE/CGE-derived cells because, in a small number of animals, many deep layer neurons were labeled and many of them were $\mathrm{SOX}_{6}{ }^{+}, \mathrm{SST}^{+}$, or $\mathrm{PV}^{+}$, molecules known to be expressed by MGE-derived interneurons (M.T. and F.M., unpublished observations). It is also unlikely that the accumulation of interneurons in layer I in some experiments was artifactual, because a large population the interneurons labeled in layer I expressed RLN, unlike those in other layers. This characteristic expression of RLN is consistent with previous reports (Lee et al., 2010; Miyoshi et al., 2010; Ma et al., 2012). In addition, labeled subcortical structures in Group 1 were distinct from those in Group 2. Our experimental paradigm provided us an opportunity to analyze interneurons with extra-MGE/POA origins, which have not been studied extensively before.

\section{Distinct origins of neocortical interneurons in Group 1 and 2 animals}

The present finding that the laminar pattern of labeling was largely complementary between Group 1 and 2 animals suggests

\section{$\leftarrow$}

(Figure legend continued.) are indicated by arrows, whereas an NPY ${ }^{-}$interneuron extending radially oriented processes is indicated by an arrowhead. $\boldsymbol{E}, \boldsymbol{F}$, Laminar distribution of radially oriented and multipolar interneurons observed in bins of layers II/III-VI. Although both types of cells are preferentially localized to bins $2-3$, radially oriented cells are almost absent in bins $7-10$. Shown is a summary of 12 samples. Error bars indicate SD. Scale bars: $\boldsymbol{B}, 300 \mu \mathrm{m} ; \boldsymbol{C}, 30$ $\mu \mathrm{m} ; \boldsymbol{D}, 50 \mu \mathrm{m}$ in D. The scale bar in $\boldsymbol{B}$ also applies to $\boldsymbol{A}$. that the embryonic origin of labeled interneurons is distinct between the two groups. This hypothesis is supported by the finding that distinct subcortical structures were labeled between the two groups, with rostrally located structures being labeled in Group 1 more than in Group 2 (Fig. 5). Furthermore, labeled interneurons showed distinct neurochemical properties between the two groups: The major population of labeled interneurons in Group 2 animals, namely layer I interneurons, predominantly expressed RLN, but not VIP or NPY, whereas none of these neurochemical markers was predominantly expressed by layer II/III interneurons (Fig. 6A), which is the major labeled population in Group 1. The most plausible explanation for these findings is that interneurons labeled in Groups 1 and 2 originated from distinct PDs (Fig. 8).

\section{Possible origins of neocortical interneurons labeled in Group 1 and Group 2 animals}

Where are the PDs labeled in Group 1 and 2 animals? The present findings indicate that labeled subcortical structures tend to be more rostrally located in Group 1 than in Group 2 animals. In Group 2 animals, the hypothalamus, a caudally located subcortical structure, was labeled, whereas the rostral striatum was not. In addition, amygdalar nuclei, which are also located caudally, were more extensively labeled in Group 2 animals, whereas rostrally located structures such as the rostral striatum and olfactory bulb were labeled only in Group 1 animals. These findings suggest that the interneurons labeled in Group 1 and Group 2 animals originated from a rostral and a caudal part of the CGE, respectively.

However, given that LGE is located rostrally to the CGE, the possibility that the PD for Group 1 animals is located in the LGE cannot be excluded. Neocortical interneurons were originally thought to be derived from the LGE based on a genetic study 
(Anderson et al., 1997) and tracing studies using rat embryos injected with lipophilic dyes (de Carlos et al., 1996; Tamamaki et al., 1997). The interpretation of these results came into question with the findings that the MGE is an origin for interneurons (Lavdas et al., 1999; Sussel et al., 1999; Wichterle et al., 1999), that MGE-derived interneurons migrate through the LGE (Anderson et al., 2001; Wichterle et al., 2001), and that in vivo transplantation studies failed to show a LGE origin of cortical interneurons (Wichterle et al., 2001; Nery et al., 2002). Nevertheless, there are several lines of evidence consistent with the notion that the LGE gives rise to some cortical interneurons. First, Sp8, a transcription factor that is expressed in the LGE and dorsal CGE, is expressed in a migratory stream of cells entering the neocortex from the dorsal LGE (Ma et al., 2012). Second, a genetic fate mapping study using $N k x 6.2$, the expression of which is highest at the LGE-MGE boundary, found that a substantial number of $\mathrm{VIP}^{+}$cells, which originate from the LGE/CGE (Lee et al., 2010; Miyoshi et al., 2010; Rubin et al., 2010; Ma et al., 2012), were labeled in the neocortex in addition to $\mathrm{PV}^{+}$and $\mathrm{SST}^{+}$cells, which originate from the MGE (Sousa et al., 2009). Third, slice culture experiments suggested that the LGE is a mitotic origin of a small number of cortical GABAergic interneurons (Anderson et al., 2001; Cai et al., 2013). Finally, in the current study, striatal projection neurons and olfactory granule cells, which are thought to originate from the LGE (Deacon et al., 1994; Olsson et al., 1995; Wichterle et al., 2001; Stenman et al., 2003; Xu et al., 2004; Tucker et al., 2006), were labeled. Therefore, it is possible that at least some neocortical interneurons labeled in Group 1 animals originated from the LGE.

An alternative possibility is that IUE in Group 1 animals targeted the region encompassing the LGE and a rostral part of the CGE, whereas that in Group 2 targeted the rest of the CGE. In this scenario, the labeling of LGE-derived subcortical structures can be explained without assuming the LGE origin of neocortical interneurons. Rather, LGE progenitors could give rise to subcortical structures such as striatal and olfactory granule cells, whereas a rostral part of the CGE could give rise to layers II/III-VI cortical interneurons.

In any case, the present results demonstrated that the laminar fate of LGE/CGE-derived interneurons is dependent on spatially distinct PDs within the LGE/CGE (Fig. 8) and possibly separated rostrocaudally.

\section{Variation in molecular expression and morphology of layers II/III-VI interneurons}

We found two major types of labeled interneurons in layers II/ III-VI of Group 1 animals: one had elongated radial processes and preferentially expressed VIP and the other had multiple oriented processes and preferentially expressed NPY. These two types of interneurons showed slightly different laminar distributions (Fig. $7 E, F$ ). We found that the ratio of interneurons with radially oriented processes to multipolar cells varied substantially from animal to animal. Given that labeled PDs may also vary from animal to animal, a plausible explanation for this finding is that there are sub-PDs within the PD for Group 1 interneurons that generate preferentially one of the two cell types (Fig. 8).

\section{Conclusion}

The laminar distribution of neurons generally depends on the timing of neurogenesis. However, the laminar fate of LGE/CGEderived neocortical interneurons does not depend on their birthdate (Miyoshi et al., 2010). The present results indicate that subdomains within the LGE/CGE generate distinct sets of in- terneurons with distinct laminar fate. Our results further suggest that these subdomains are the LGE and CGE or the LGE/a rostral part of the CGE and a caudal part of the CGE.

\section{References}

Altman J, Bayer SA (1981) Time of origin of neurons of the rat superior colliculus in relation to other components of the visual and visuomotor pathways. Exp Brain Res 42:424-434. Medline

Altman J, Bayer SA (1987) Development of the precerebellar nuclei in the rat: IV. The anterior precerebellar extramural migratory stream and the nucleus reticularis tegmenti pontis and the basal pontine gray. J Comp Neurol 257:529-552. CrossRef Medline

Anderson SA, Eisenstat DD, Shi L, Rubenstein JL (1997) Interneuron migration from basal forebrain to neoneocortex: dependence on Dlx genes. Science 278:474-476. CrossRef Medline

Anderson SA, Marín O, Horn C, Jennings K, Rubenstein JL (2001) Distinct cortical migrations from the medial and lateral ganglionic eminences. Development 128:353-363. Medline

Angevine JB Jr, Sidman RL (1961) Autoradiographic study of cell migration during histogenesis of cerebral cortex in the mouse. Nature 192:766-768. Medline

Bartolini G, Ciceri G, Marín O (2013) Integration of GABAergic interneurons into cortical cell assemblies: lessons from embryos and adults. Neuron 79:849-864. CrossRef Medline

Batista-Brito R, Rossignol E, Hjerling-Leffler J, Denaxa M, Wegner M, Lefebvre V, Pachnis V, Fishell G (2009) The cell-intrinsic requirement of Sox6 for cortical interneuron development. Neuron 63:466-481. CrossRef Medline

Butt SJ, Fuccillo M, Nery S, Noctor S, Kriegstein A, Corbin JG, Fishell G (2005) The temporal and spatial origins of cortical interneurons predict their physiological subtype. Neuron 48:591-604. CrossRef Medline

Cai Y, Zhang Q, Wang C, Zhang Y, Ma T, Zhou X, Tian M, Rubenstein JL, Yang Z (2013) Nuclear receptor COUP-TFII-expressing neocortical interneurons are derived from the medial and lateral/caudal ganglionic eminence and define specific subsets of mature interneurons. J Comp Neurol 521:479-497. CrossRef Medline

Cavanagh ME, Parnavelas JG (1989) Development of vasoactive-intestinalpolypeptide-immunoreactive neurons in the rat cccipital cortex: a combined immunohistochemical-autoradiographic study. J Comp Neurol 284:637-645. CrossRef Medline

Cepko CL, Austin CP, Yang X, Alexiades M, Ezzeddine D (1996) Cell fate determination in the vertebrate retina. Proc Natl Acad Sci U S A 93: 589-595. CrossRef Medline

Deacon TW, Pakzaban P, Isacson O (1994) The lateral ganglionic eminence is the origin of cells committed to striatal phenotypes: neural transplantation and developmental evidence. Brain Res 668:211-219. CrossRef Medline

de Carlos JA, López-Mascaraque L, Valverde F (1996) Dynamics of cell migration from the lateral ganglionic eminence in the rat. J Neurosci 16: 6146-6156. Medline

Fairén A, Cobas A, Fonseca M (1986) Times of generation of glutamic acid decarboxylase immunoreactive neurons in mouse somatosensory neocortex. J Comp Neurol 251:67-83. CrossRef Medline

Flames N, Pla R, Gelman DM, Rubenstein JL, Puelles L, Marín O (2007) Delineation of multiple subpallial progenitor domains by the combinatorial expression of transcriptional codes. J Neurosci 27:9682-9695. CrossRef Medline

Fogarty M, Grist M, Gelman D, Marín O, Pachnis V, Kessaris N (2007) Spatial genetic patterning of the embryonic neuroepithelium generates GABAergic interneuron diversity in the adult neocortex. J Neurosci 27: 10935-10946. CrossRef Medline

Gelman DM, Marín O (2010) Generation of interneuron diversity in the mouse cerebral neocortex. Eur J Neurosci 31:2136-2141. CrossRef Medline

Gelman DM, Martini FJ, Nóbrega-Pereira S, Pierani A, Kessaris N, Marín O (2009) The embryonic preoptic area is a novel source of cortical GABA ergic interneurons. J Neurosci 29:9380-9389. CrossRef Medline

Ghanem N, Yu M, Long J, Hatch G, Rubenstein JL, Ekker M (2007) Distinct cis-regulatory elements from the Dlx1/Dlx2 locus mark different progenitor cell populations in the ganglionic eminences and different subtypes of adult cortical interneurons. J Neurosci 27:5012-5022. CrossRef Medline

Hajós F, Zilles K, Gallatz K, Schleicher A, Kaplan I, Werner L (1988) Ram- 
ification patterns of vasoactive intestinal polypeptide (Vip) cells in the rat primary visual-neocortex: an immunohistochemical study. Anat Embryol 178:197-206. CrossRef Medline

Kawaguchi Y, Kubota Y (1996) Physiological and morphological identification of somatostatin- or vasoactive intestinal polypeptide-containing cells among GABAergic cell subtypes in rat frontal neocortex. J Neurosci 16: 2701-2715. Medline

Kawakami K, Imanaka K, Itoh M, Taira M (2004a) Excision of the Tol2 transposable element of the medaka fish Oryzias latipes in Xenopus laevis and Xenopus tropicalis. Gene 338:93-98. CrossRef Medline

Kawakami K, Takeda H, Kawakami N, Kobayashi M, Matsuda N, Mishina M (2004b) A transposon-mediated gene trap approach identifies developmentally regulated genes in zebrafish. Dev Cell 7:133-144. CrossRef Medline

Kepecs A, Fishell G (2014) Interneuron cell types are fit to function. Nature 505:318-326. CrossRef Medline

Kita Y, Kawakami K, Takahashi Y, Murakami F (2013) Development of cerebellar neurons and glias revealed by in utero electroporation: Golgilike labeling of cerebellar neurons and glias. PLoS One 8:e70091. CrossRef Medline

Lavdas AA, Grigoriou M, Pachnis V, Parnavelas JG (1999) The medial ganglionic eminence gives rise to a population of early neurons in the developing cerebral neocortex. J Neurosci 19:7881-7888. Medline

Lee S, Hjerling-Leffler J, Zagha E, Fishell G, Rudy B (2010) The largest group of superficial neocortical GABAergic interneurons expresses ionotropic serotonin receptors. J Neurosci 30:16796-16808. CrossRef Medline

Ma T, Zhang Q, Cai Y, You Y, Rubenstein JL, Yang Z (2012) A subpopulation of dorsal lateral/caudal ganglionic eminence-derived neocortical interneurons expresses the transcription factor Sp8. Cereb Cortex 22: 2120-2130. CrossRef Medline

Markram H, Toledo-Rodriguez M, Wang Y, Gupta A, Silberberg G, Wu C (2004) Interneurons of the neocortical inhibitory system. Nat Rev Neurosci 5:793-807. CrossRef Medline

Martinez-Galan JR, Moncho-Bogani J, Caminos E (2014) Expression of calcium-binding proteins in layer 1 reelin-immunoreactive cells during rat and mouse neocortical development. J Histochem Cytochem 62: 60-69. CrossRef Medline

Miller MW (1985) Cogeneration of retrogradely labeled corticocortical projection and GABA-immunoreactive local circuit neurons in cerebral cortex. Brain Res 355:187-192. Medline

Miyoshi G, Fishell G (2011) GABAergic interneuron lineages selectively sort into specific cortical layers during early postnatal development. Cereb Cortex 21:845-852. CrossRef Medline

Miyoshi G, Butt SJ, Takebayashi H, Fishell G (2007) Physiologically distinct temporal cohorts of cortical interneurons arise from telencephalic Olig2expressing precursors. J Neurosci 27:7786-7798. CrossRef Medline

Miyoshi G, Hjerling-Leffler J, Karayannis T, Sousa VH, Butt SJ, Battiste J, Johnson JE, Machold RP, Fishell G (2010) Genetic fate mapping reveals that the caudal ganglionic eminence produces a large and diverse population of superficial cortical interneurons. J Neurosci 30:1582-1594. CrossRef Medline

Miyoshi G, Young A, Petros T, Karayannis T, McKenzie Chang M, Lavado A, Iwano T, Nakajima M, Taniguchi H, Huang ZJ, Heintz N, Oliver G, Matsuzaki F, Machold RP, Fishell G (2015) Prox1 regulates the subtypespecific development of caudal ganglionic eminence-derived GABAergic cortical interneurons. J Neurosci 35:12869-12889. CrossRef Medline

Nery S, Fishell G, Corbin JG (2002) The caudal ganglionic eminence is a source of distinct cortical and subcortical cell populations. Nat Neurosci 5:1279-1287. CrossRef Medline

Olsson M, Campbell K, Wictorin K, Björklund A (1995) Projection neurons in fetal striatal transplants are predominantly derived from the lateral ganglionic eminence. Neuroscience 69:1169-1182. CrossRef Medline

Rubin AN, Alfonsi F, Humphreys MP, Choi CK, Rocha SF, Kessaris N (2010) The germinal zones of the basal ganglia but not the septum generate GABAergic interneurons for the neocortex. J Neurosci 30:12050-12062. CrossRef Medline

Rudy B, Fishell G, Lee S, Hjerling-Leffler J (2011) Three groups of interneurons account for nearly $100 \%$ of neocortical GABAergic neurons. Dev Neurobiol 71:45-61. CrossRef Medline

Rymar VV, Sadikot AF (2007) Laminar fate of cortical GABAergic interneu- rons is dependent on both birthdate and phenotype. J Comp Neurol 501:369-380. CrossRef Medline

Shinohara M, Zhu Y, Murakami F (2013) Four-dimensional analysis of nucleogenesis of the pontine nucleus in the hindbrain. J Comp Neurol 521:3340-3357. CrossRef Medline

Sousa VH, Miyoshi G, Hjerling-Leffler J, Karayannis T, Fishell G (2009) Characterization of Nkx6-2-derived neocortical interneuron lineages. Cereb Cortex 19:i1-i10. CrossRef Medline

Stenman J, Toresson H, Campbell K (2003) Identification of two distinct progenitor populations in the lateral ganglionic eminence: implications for striatal and olfactory bulb neurogenesis. J Neurosci 23:167-174. Medline

Sussel L, Marin O, Kimura S, Rubenstein JL (1999) Loss of Nkx2.1 homeobox gene function results in a ventral to dorsal molecular respecification within the basal telencephalon: evidence for a transformation of the pallidum into the striatum. Development 126:3359-3370. Medline

Takahashi T, Goto T, Miyama S, Nowakowski RS, Caviness VS Jr (1999) Sequence of neuron origin and neocortical laminar fate: relation to cell cycle of origin in the developing murine cerebral wall. J Neurosci 19: 10357-10371. Medline

Tamamaki N, Fujimori KE, Takauji R (1997) Origin and route of tangentially migrating neurons in the developing neocortical intermediate zone. J Neurosci 17:8313-8323. Medline

Tanaka DH, Maekawa K, Yanagawa Y, Obata K, Murakami F (2006) Multidirectional and multizonal tangential migration of GABAergic interneurons in the developing cerebral cortex. Development 133:2167-2176. CrossRef Medline

Tanaka DH, Yanagida M, Zhu Y, Mikami S, Nagasawa T, Miyazaki J, Yanagawa Y, Obata K, Murakami F (2009) Random walk behavior of migrating cortical interneurons in the marginal zone: time-lapse analysis in flat-mount cortex. J Neurosci 29:1300-1311. CrossRef Medline

Tanaka D, Nakaya Y, Yanagawa Y, Obata K, Murakami F (2003) Multimodal tangential migration of neocortical GABAergic neurons independent of GPIanchored proteins. Development 130:5803-5813. CrossRef Medline

Taniguchi H, Lu J, Huang ZJ (2013) The spatial and temporal origin of chandelier cells in mouse neoneocortex. Science 339:70-74. CrossRef Medline

Teissier A, Griveau A, Vigier L, Piolot T, Borello U, Pierani A (2010) A novel transient glutamatergic population migrating from the pallial-subpallial boundary contributes to neocortical development. J Neurosci 30:1056310574. CrossRef Medline

Torigoe M, Yamauchi K, Zhu Y, Kobayashi H, Murakami F (2015) Association of astrocytes with neurons and astrocytes derived from distinct progenitor domains in the subpallium. Sci Rep 5:12258. CrossRef Medline

Tucker ES, Polleux F, LaMantia AS (2006) Position and time specify the migration of a pioneering population of olfactory bulb interneurons. Dev Biol 297:387-401. CrossRef Medline

Valcanis H, Tan SS (2003) Layer specification of transplanted interneurons in developing mouse neocortex. J Neurosci 23:5113-5122. Medline

Vucurovic K, Gallopin T, Ferezou I, Rancillac A, Chameau P, van Hooft JA, Geoffroy H, Monyer H, Rossier J, Vitalis T (2010) Serotonin 3A receptor subtype as an early and protracted marker of cortical interneuron subpopulations. Cereb Cortex 20:2333-2347. CrossRef Medline

Wichterle H, Garcia-Verdugo JM, Herrera DG, Alvarez-Buylla A (1999) Young neurons from medial ganglionic eminence disperse in adult and embryonic brain. Nat Neurosci 2:461-466. CrossRef Medline

Wichterle H, Turnbull DH, Nery S, Fishell G, Alvarez-Buylla A (2001) In utero fate mapping reveals distinct migratory pathways and fates of neurons born in the mammalian basal forebrain. Development 128 : 3759-3771. Medline

Wonders CP, Anderson SA (2006) The origin and specification of cortical interneurons. Nat Rev Neurosci 7:687-696. CrossRef Medline

Wonders CP, Taylor L, Welagen J, Mbata IC, Xiang JZ, Anderson SA (2008) A spatial bias for the origins of interneuron subgroups within the medial ganglionic eminence. Dev Biol 314:127-136. CrossRef Medline

XuQ, Cobos I, De La CruzE, Rubenstein JL, Anderson SA (2004) Origins of cortical interneuron subtypes. J Neurosci 24:2612-2622. CrossRef Medline

Xu Q, Tam M, Anderson SA (2008) Fate mapping Nkx2.1-lineage cells in the mouse telencephalon. J Comp Neurol 506:16-29. CrossRef Medline

Yoshida A, Yamaguchi Y, Nonomura K, Kawakami K,Takahashi Y, Miura M (2010) Simultaneous expression of different transgenes in neurons and glia by combining in utero electroporation with the Tol2 transposon-mediated gene transfer system. Genes Cells 15:501-512. CrossRef Medline 